\title{
Optical and structural-chemistry of SnS nanocrystals prepared by thermal decomposition of bis(N-di-isopropyl-N-octyl dithiocarbamato)tin(II) complex for promising materials in solar cell applications
}

\author{
Edson L. Meyer ${ }^{2} \cdot$ Johannes Z. Mbese ${ }^{1}$ (D) $\cdot$ Mojeed A. Agoro ${ }^{1} \cdot$ Raymond Taziwa $^{3}$
}

Received: 19 August 2019 / Accepted: 14 January 2020 / Published online: 29 January 2020

(c) The Author(s) 2020

\begin{abstract}
Mixed ligand precursor complex bis(N-di-isopropyl-N-octyl dithiocarbamato)tin(II) complex was synthesized from its respective dithiocarbamate ligands, characterized and thermalized through thermogravimetric analysis to yield tin sulfide ( $\mathrm{SnS}$ ) nanocrystals. The thermal decomposition pattern was recorded as a function of the required temperature for the formation of the $\mathrm{SnS}$ nanocrystals at $360{ }^{\circ} \mathrm{C}$. The $\mathrm{SnS}$ nanocrystals were characterized using optical, vibrational, structural and morphological analyses instruments. The obtained orthorhombic phase $\mathrm{SnS}$ nanocrystals showed indirect and direct optical energy band gaps close to the $1.5 \mathrm{eV}$ of the bulk $\mathrm{SnS}$.
\end{abstract}

Keywords Mixed ligand precursor complex $\cdot$ Thermogravimetric analysis $\cdot \mathrm{SnS}$ nanocrystals $\cdot$ Thermal decomposition pattern · Orthorhombic phase

\section{Introduction}

Technological important semiconductor materials such as tin sulfide $(\mathrm{SnS})$ nanocrystals have become the scientist's hotspot due to their excellent properties of direct band gap of $1.30-1.43 \mathrm{eV}$ and orthorhombic structure. SnS possess effective absorption coefficient than CIGS, CdTe and has display good potential in Photovoltaic (PV) applications as absorber layers in thin film solar cells (Devika et al. 2009; Stavrinadis et al. 2010; Baig et al. 2018), anode material in lithium ion batteries (Vaughn et al. 2012; Talapin et al. 2009), photodetectors (Zhou et al. 2016), photocatalysis (Tang et al. 2011, 2016), optoelectronic devices (Koteeswara Reddy et al. 2007; Wang et al. 2017), photovoltaic (Ninan et al. 2016;

Johannes Z. Mbese

jmbese@ufh.ac.za; magoro@ufh.ac.za

1 Department of Chemistry, University of Fort Hare, Private Bag X1314, Alice 5700, South Africa

2 Fort Hare Institute of Technology, University of Fort Hare, Private Bag X1314, Alice 5700,

South Africa

3 Department of Applied Sciences, Walter Sisulu University, Potsdam Campus, East London 5200, South Africa 
Stavrinadis et al. 2010) and gas sensing (Wang et al. 2016). Overwhelming interest in SnS nanoparticles applications are related to its low toxicity, its low cost, the abundance of sulfur $(\mathrm{S})$ and tin $(\mathrm{Sn})$ elements in the nature. Tin Sulfide is a unique important binary semiconductor material of IV-VI exhibiting $\mathrm{p}$ and $\mathrm{n}$ type behaviour, with direct and indirect band gaps of 1.3 and $1.09 \mathrm{eV}$, respectively, which is close to the ideal band gap $1.5 \mathrm{eV}$ with highest photovoltaic conversion efficiency (Xu et al. 2012; Sohila et al. 2011; Hickey et al. 2008). It has been reported to have optical absorption coefficient $\left(>10^{4} \mathrm{~cm}^{-1}\right)$ and conductivity (hole mobility $=90 \mathrm{~cm}^{2} \mathrm{~V}^{-1} \mathrm{~s}^{-1}$ ) in single crystals, across the near-infrared and visible spectrum which coincide with the maximum efficiency for optimum band gap according to Shockley-Queisser limit within the AM 1.5 solar spectrum (Cifuentes et al. 2006; Greyson et al. 2006; Tanusevski 2003; Baig et al. 2018).

Meanwhile, the molecular precursors compounds such as tin or organotin dithiocarbamates have received tremendous attention in their potential applications in non-linear optical materials, biology, industry, agriculture, chemistry and some have been found to be pharmacologically active (Muthalib et al. 2011; Awang et al. 2016). Apart from the singlesource molecular precursor (SSMP) method our research group has previously reported (Mbese and Ajibade 2017; Mbese and Ajibade 2018), researchers have synthesized SnS nanocrystals using dual source precursors methods such as thermal evaporation (Shao et al. 2017; Kawano et al. 2015), spray pyrolysis (Sall et al. 2016; Akbari and Rozati 2015), electrodeposition (Kafashan et al. 2017; Ichimura et al. 2000), radiofrequency (RF) sputtering (Banai et al. 2016; Seol et al. 2003), sonochemical method (Park et al. 2014; Henry et al. 2015), electron beam (EB) evaporation (Zhao et al. 2018) and chemical bath deposition (Al-Shakban et al. 2019; Kevin et al. 2015a, b). The advantage of using SSMP is that, precursor complexes are stoichiometric synthesized to contain the desired elements so that precursor complexes thermally decompose to yield materials of specific compositions. To the best of our knowledge, there are no reports on the thermal decomposition of mixed ligands complex of tin(II) dithiocarbamate as a single-source molecular precursor to the formation of $\mathrm{SnS}$ nanoparticles. In this contribution, mixed ligand precursor complex bis(N-di-isopropyl-N-octyl dithiocarbamato)tin(II) complex was synthesized, characterized and thermalized through thermogravimetric analysis to yield $\mathrm{SnS}$ nanocrystals.

\section{Experimental procedures}

\subsection{Preparation of the nanocrystals}

In this paper, the preparation of $\mathrm{SnS}$ nanocrystals by thermal decomposition of bis(N-diisopropyl-N-octyl dithiocarbamato)tin(II) complex is described. Dithiocarbamates ligands and mixed ligand precursor complex were synthesized, separately. In a typical experiment as shown in reaction Scheme 1, ammonium N-diisopropyldithiocarbamate (Di-IsoprDTC) ligand was prepared by a modified literature method (Mbese and Ajibade 2014). $30 \mathrm{~mL}$ of concentrated ammonia solution was added slowly to $9.64 \mathrm{~mL}(0.1 \mathrm{~mol})$ di-isopropylamine in an ice cold mixture at $0-5{ }^{\circ} \mathrm{C}$. To this mixture, $6.04 \mathrm{~mL}(0.1 \mathrm{~mol})$ of carbon disulfide was added drop-wise through separating funnel with constant stirring in an ice bath and refluxed for a further $2 \mathrm{~h}$ at room temperature. The resulting yellowish solid obtained was filtered by suction and rinsed three times with cold ethanol. Di-IsoprDTC, selected IR $\left(\mathrm{ATR}, \mathrm{cm}^{-1}\right) v: 1469$ (N-CSS), $2975(\mathrm{C}-\mathrm{H}) \mathrm{sp}^{3}, 1650$ (C=S), 3378 (N-H str.). Selected ${ }^{1} \mathrm{H}-\mathrm{NMR}$ (400.1 MHz, DMSO- $\left.d_{6}, \mathrm{ppm}\right): \delta=2.50$ (6H, bs, DMSO- $\left.d_{6}\right), 3.28-3.37$, $(6 \mathrm{H}$, 
<smiles>CC(C)NC(C)C</smiles>

Di-isopropylamine

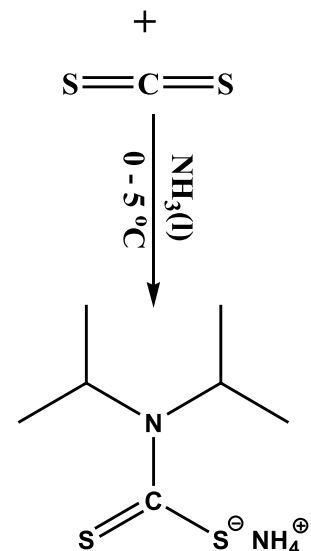

Di-isoprDTC<smiles>CCCCCCCCN</smiles>

octan-1-amine

$+$

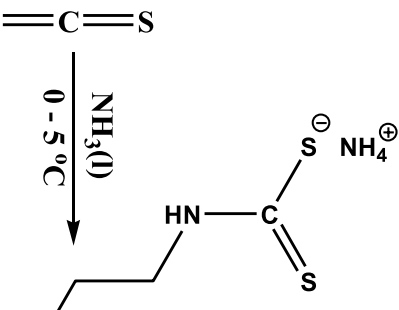

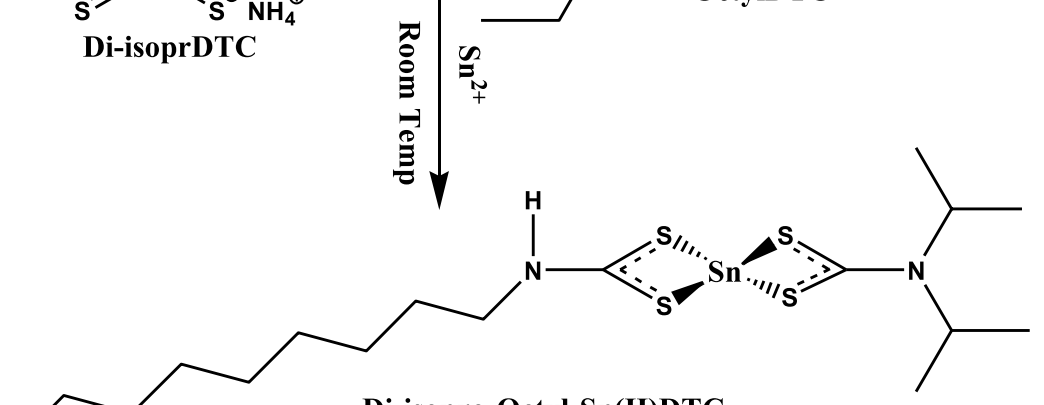

Di-isopro-Octyl-Sn(II)DTC

Scheme 1 Synthesis of bis(N-di-isopropyl-N-octyl dithiocarbamato)tin(II) complex

$\mathrm{m},-\mathrm{CH}_{3}$ ). Yield: $(89.74 \%)$. Ammonium octyldithiocarbamate (OctylDTC) ligands was prepared following the similar procedure, using $16.5480 \mathrm{~mL}(0.1 \mathrm{~mol})$ of octylamine. OctylDTC, selected IR (ATR, $\mathrm{cm}^{-1}$ ) v: 1470 (N-CSS), 939 (C-S), 3395 (N-H str), 2920 $v(\mathrm{C}-\mathrm{H}) \mathrm{sp}^{3}$. Selected ${ }^{1} \mathrm{H}-\mathrm{NMR}\left(400.1 \mathrm{MHz}, \mathrm{DMSO}-d_{6}, \mathrm{ppm}\right): \delta=1.3\left(2 \mathrm{H}, \mathrm{t},-\mathrm{CH}_{2}\right), 3.5$ $(2 \mathrm{H}, \mathrm{s},-\mathrm{NH}), 0.9\left(3 \mathrm{H}, \mathrm{t},-\mathrm{CH}_{3}\right)$. Yield: $(76.45 \%)$.

For the synthesis of bis(N-di-isopropyl-N-octyl dithiocarbamato)tin(II) complex, about $0.6953 \mathrm{~g}(2.5 \mathrm{mmol})$ of $\mathrm{SnCl}_{2} \cdot 2 \mathrm{H}_{2} \mathrm{O}$ was dissolved in $15 \mathrm{~mL}$ of distilled water and added to $0.4859 \mathrm{~g}(2.5 \mathrm{mmol})$ of Di-IsoprDTC and $0.5550 \mathrm{~g}(2.5 \mathrm{mmol})$ of OctylDTC dissolved in $15 \mathrm{~mL}$ of distilled water for both ligands at ratio $1: 1: 1$. The reaction mixtures were stirred for $2 \mathrm{~h}$ at room temperature. The precipitated products were filtered and washed three times with $25 \mathrm{~mL}$ of cold methanol. The resulting dithiocarbamate complexes was dried at room temperature. Selected IR (ATR, $\left.\mathrm{cm}^{-1}\right) v$ : $1511(\mathrm{C}-\mathrm{N}), 1033(\mathrm{C}-\mathrm{S}), 3310(\mathrm{~N}-\mathrm{H}), 577$ $v(\mathrm{Sn}-\mathrm{S}), 2953\left(\mathrm{CH}_{3}\right)$. Selected ${ }^{1} \mathrm{H}-\mathrm{NMR}\left(400.1 \mathrm{MHz}, \mathrm{DMSO}-d_{6}, \mathrm{ppm}\right): \delta=2.50(6 \mathrm{H}, \mathrm{bs}$, DMSO-d $)_{6}, 1.3\left(2 \mathrm{H} \mathrm{s},-\mathrm{CH}_{2}\right), 0.9\left(3 \mathrm{H} \mathrm{t},-\mathrm{CH}_{3}\right)$.

Synthesis of SnS nanocrystals were obtained through high-temperature thermal decomposition of bis(N-di-isopropyl-N-octyl dithiocarbamato)tin(II) complex using Perkin Elmer 
TGA 4000 ThermoGravimetric Analyser (TGA). About $25 \mathrm{mg}$ of the complex was loaded into an alumina pan and weight changes was recorded as a function of temperature for a $10{ }^{\circ} \mathrm{C} \mathrm{min}{ }^{-1}$ temperature gradient between 30 and $900{ }^{\circ} \mathrm{C}$. A purge gas of flowing nitrogen at a rate of $20 \mathrm{~mL} \mathrm{~min}{ }^{-1}$ was used. At temperatures between 360 and $900{ }^{\circ} \mathrm{C}$, the complex end-product was converted into residue, which was expected for the formation of $\mathrm{SnS}$ nanocrystals from the residue obtain from the TGA.

\section{Characterization methods}

A Perkin Elmer Lambda 25 UV-vis spectrophotometer was employed to carry out optical absorption properties at room temperature. The photoluminescence of the nanoparticles was measured using Perkin Elmer LS 45 fluorimeter. Fourier Transform InfraRed (FTIR) nets were carried out by the Spectrum Two model Perkin Elmer FTIR spectrophotometer at a $4 \mathrm{~cm}^{-1}$ resolution in Attenuated Total Reflection (ATR) mode using a ceramic light source, $\mathrm{KBr} / \mathrm{Ge}$ beam splitter, and a lithium tantalate $\left(\mathrm{LiTaO}_{3}\right)$ detector. The spectra of FTIR were scanned between 370 and $4000 \mathrm{~cm}^{-1}$. Field Emission Scanning Electron Microscope (FE-SEM) Zeiss Auriga SEM outfitted with Energy Dispersive X-Ray Spectroscopy (EDS) with Smart SEM programming was utilized to study the elemental and morphlogical properties of nanoparticles at a quickening voltage of $30 \mathrm{kV}$. The X-Ray Diffraction (XRD) measurements were done on a Rigaku Ultima IV X-ray diffractometer using a $\mathrm{Cu}-\mathrm{K} \alpha$ radiation $(\lambda=0.15406 \mathrm{~nm})$. JEOL JEM 2100 High Resolution Transmission Electron Microscope (HRTEM) operating at $200 \mathrm{kV}$ for high resolution images with selected area electron diffraction (SAED) patterns. Raman spectra of the examples were finished utilizing a Confocal Raman AFM Imaging system (WITec GmbH) alpha 300RS. A fiber coupled DPSS laser of wavelength $532 \mathrm{~nm}$ with an output power of $44 \mathrm{~mW}$ and a greatest yield control after a singlemode fiber coupling was utilized as the excitation source. Information was then gathered, utilizing a multimode fiber into a high throughput focal point based spectrograph (UHTS 300) with $300 \mathrm{~mm}$ central length and two gratings $600 \mathrm{~g} / \mathrm{mm}$ and $1800 \mathrm{~g} / \mathrm{mm}$, both blasted at $550 \mathrm{~nm}$. The UHTS 300 spectrograph is associated with a Peltier cooled back lit up CCD camera with superior to $90 \%$ QE in the visible excitation. Every spectrum was obtained at a coordination time of $1.09667 \mathrm{~s}$ and around 200 gatherings were gathered per every spectrum in the scan range of $100-1100 \mathrm{~cm}^{-1}$. Thermogravimetric analysis were carried out as mentioned above.

\section{Results and discussion}

The mixed-ligands complex bis(N-di-isopropyl-N-octyl dithiocarbamato)tin(II) complex has been prepared by simultaneously mixing of homogeneously stirred water solutions of ammonium N-diisopropyldithiocarbamate (Di-IsoprDTC) and ammonium octyldithiocarbamate (OctylDTC) ligands into the water solution of $\mathrm{SnCl}_{2} \cdot 2 \mathrm{H}_{2} \mathrm{O}$ salt, as shown in the reaction Scheme 1. The thermal decomposition behaviour of complex was studied. TGA revealed three staged degradations as seen in Fig. 1. Stage 1 around $160{ }^{\circ} \mathrm{C}$ is ascribed to the complete loss of Di-IsoprDTC ligand moiety due to its lower melting and boiling point. Stage 2 around $210{ }^{\circ} \mathrm{C}$ is predicted to be the decomposition of OctylDTC moiety, which has high boiling or melting point compared to the Di-IsoprDTC. The final decomposition stage $3\left(250-360{ }^{\circ} \mathrm{C}\right)$ shows loss of organic moieties of the ligands leaving the residual 


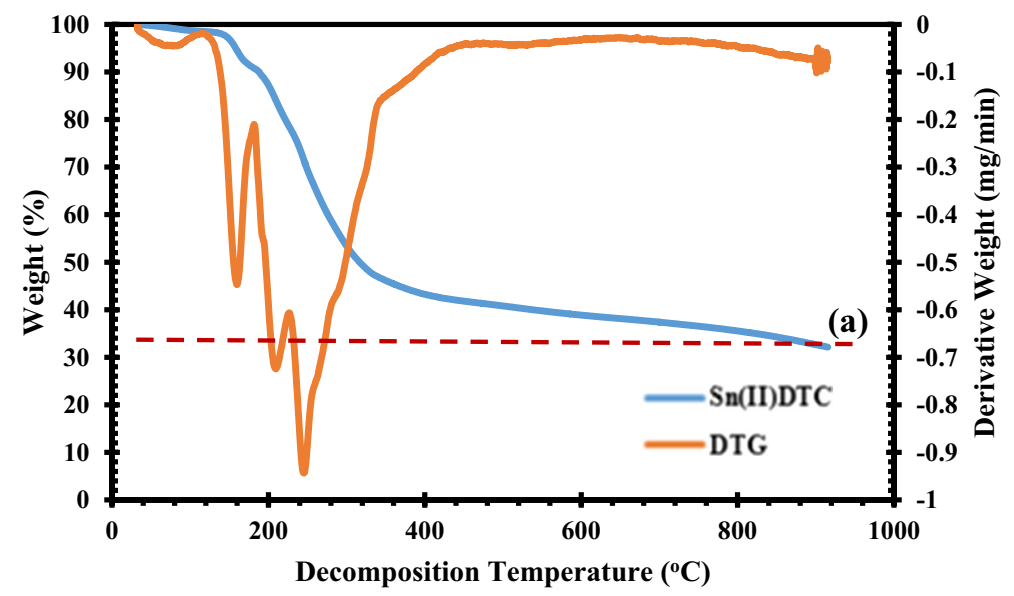

Fig. 1 TGA and Derivative thermogravimetric (DTG) patterns of bis(N-di-isopropyl-N-octyl dithiocarbamato)tin(II) complex. Horizontal dotted line (a) represents the 34\% theoretical weight loss required for the formation of $\mathrm{SnS}$ nanocrystals

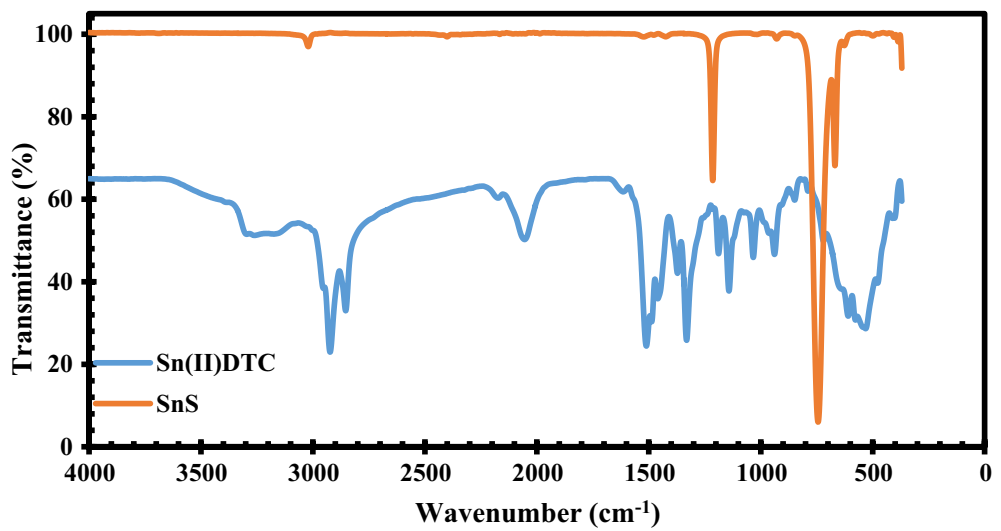

Fig. 2 FTIR spectra of bis(N-di-isopropyl-N-octyl dithiocarbamato)tin(II) complex Sn(II)DTC and its corresponding $\mathrm{SnS}$ nanocrystals

weight that leads to the formation of SnS nanocrystals. The horizontal dotted line (a) represents the 34\% theoretical weight loss required for the formation of $\mathrm{SnS}$ nanocrystals (Kevin et al. 2015a, b). The observed values are in agreement with theoretical values, indicating high thermal stability of the precursor complex.

FTIR spectra of bis(N-di-isopropyl-N-octyl dithiocarbamato)tin(II) complex ( $\mathrm{Sn}$ (II) DTC and its corresponding SnS nanocrystals is shown in Fig. 2. The compound bis(N-diisopropyl-N-octyl dithiocarbamato)tin(II) complex ( $\mathrm{Sn}$ (II)DTC) shows thioureide band in the region $1460-1511 \mathrm{~cm}^{-1}$ due to $v(\mathrm{C}-\mathrm{N})$ of NCS. The vibration frequency that appears as doublet splitting bands in the IR region $937-1035 \mathrm{~cm}^{-1}$ is assigned to $v(\mathrm{C}-\mathrm{S})$ of CSS, confirming the bidentate nature dithiocarbamates. The strong vibration frequency band at $535 \mathrm{~cm}^{-1}$ indicate the existence of Sn-S bond (Muthalib et al. 2011). In the FTIR spectrum of $\mathrm{SnS}$ nanocrystals, this band was shifted to higher frequency $\left(669 \mathrm{~cm}^{-1}\right)$, confirming the 


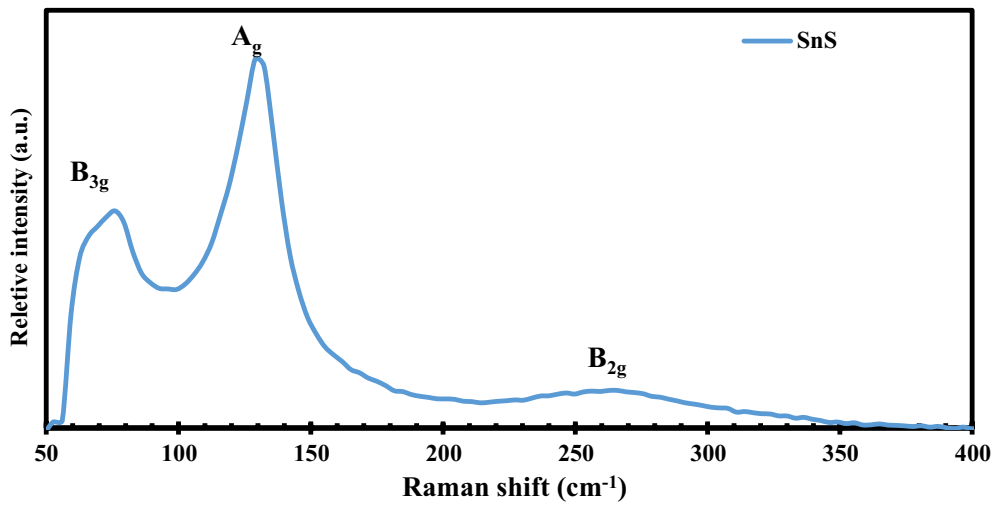

Fig. 3 Raman spectrum for $\mathrm{SnS}$ nanocrystals from the decomposed complex residue

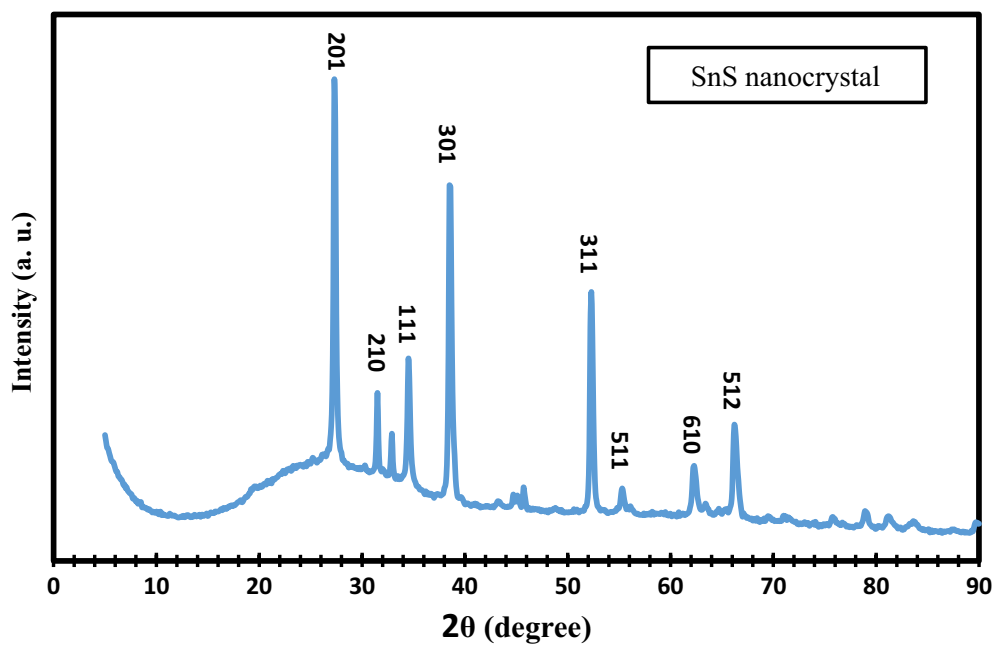

Fig. 4 XRD pattern of SnS nanocrystals obtained from the decomposed complex residue during thermolysis, showing reference pattern of orthorhombic structure SnS (ICCD pattern No. 00-039-0354)

successful formation of SnS nanocrystals. Raman spectroscopy (as shown in Fig. 3) was studied to confirm the composition of the nanocrystals. Three diagnostic Raman shifts located at 270.0, 132.3 and $79.4 \mathrm{~cm}^{-1}$ are observed, which correspond to the $\mathrm{B}_{2 \mathrm{~g}}, \mathrm{~A}_{\mathrm{g}}$ and $\mathrm{B}_{3 \mathrm{~g}}$ modes of $\mathrm{SnS}$ nanocrystals, respectively. This value is contrary to the report by Sebastian et al. (2019) with the values of 46, 69, 96, 116, 174 and $218 \mathrm{~cm}^{-1}$. Previous study on vibrational modes for $\mathrm{SnS}$ nanoparticles was detected at 77, 95, 163, 191, and $220 \mathrm{~cm}^{-1}$ which was in agreement with the report by Chowdhury et al. (2016). Vibrational modes observed in this work show a slight shift towards similar wave number in comparison with this study which is attributed to phonon confinement.

The powder X-ray diffraction pattern (Fig. 4) confirmed the orthorhombic structure of $\mathrm{SnS}$ nanocrystals corresponding to the reference code (ICCD Pattern No. 00-0390354) (Kumar et al. 2014; Kafashan et al. 2017; Jamali-Sheini et al. 2018), having lattice 
parameters $a=0.4329 \mathrm{~nm}, \mathrm{~b}=1.1192 \mathrm{~nm}$ and $\mathrm{c}=0.3984 \mathrm{~nm}$, as shown in Fig. 4 . The XRD diffraction peaks at $26.03^{\circ}$ to $66.04^{\circ}$ for $\mathrm{SnS}$ with Miller indices of (201), (210), (111), (301), (311), (511), (610) and (512), respectively, in agreement with the SnS nanocrystals literature (Kumar et al. 2014; Kafashan et al. 2017; Oda et al. 2014). On the other hand less prominent peak was observed at $2 \theta=34.5^{\circ}$ which corresponds to the $\left(\begin{array}{lll}1 & 1 & 1\end{array}\right)$ reflection plane has compare to the report by Henry et al. (2013) with prominent peak. The narrow peaks indicate nano-size particles that are just above the quantum dots size range. Average crystallite size estimated from Scherrer equation (Ilkhechi et al. 2016) was obtained to be $14 \mathrm{~nm}$, which was in close agreement to those observed in HRTEM. The excess capping agent used during synthesis is ascribe to the growth process through nucleation controlled given rise to a preferential orientation of $\mathrm{SnS}$.

SEM images of SnS nanocrystals with the EDS spectrum was inset with observed elements, HRTEM images of SnS nanocrystals showing fringes with inset selected area electron diffraction (SAED) pattern, d-spacing and particle sizes are shown in Fig. 5. The HRTEM image of a single $\mathrm{SnS}$ nanocrystals clearly displays defined lattice fringes with a $3.647 \mathrm{~nm}$ d-spacing, corresponding to the (111) planes, SAED pattern exhibiting distinct diffraction rings corresponding to the (111), (200), and (311) of the orthorhombic phase of SnS (shown in
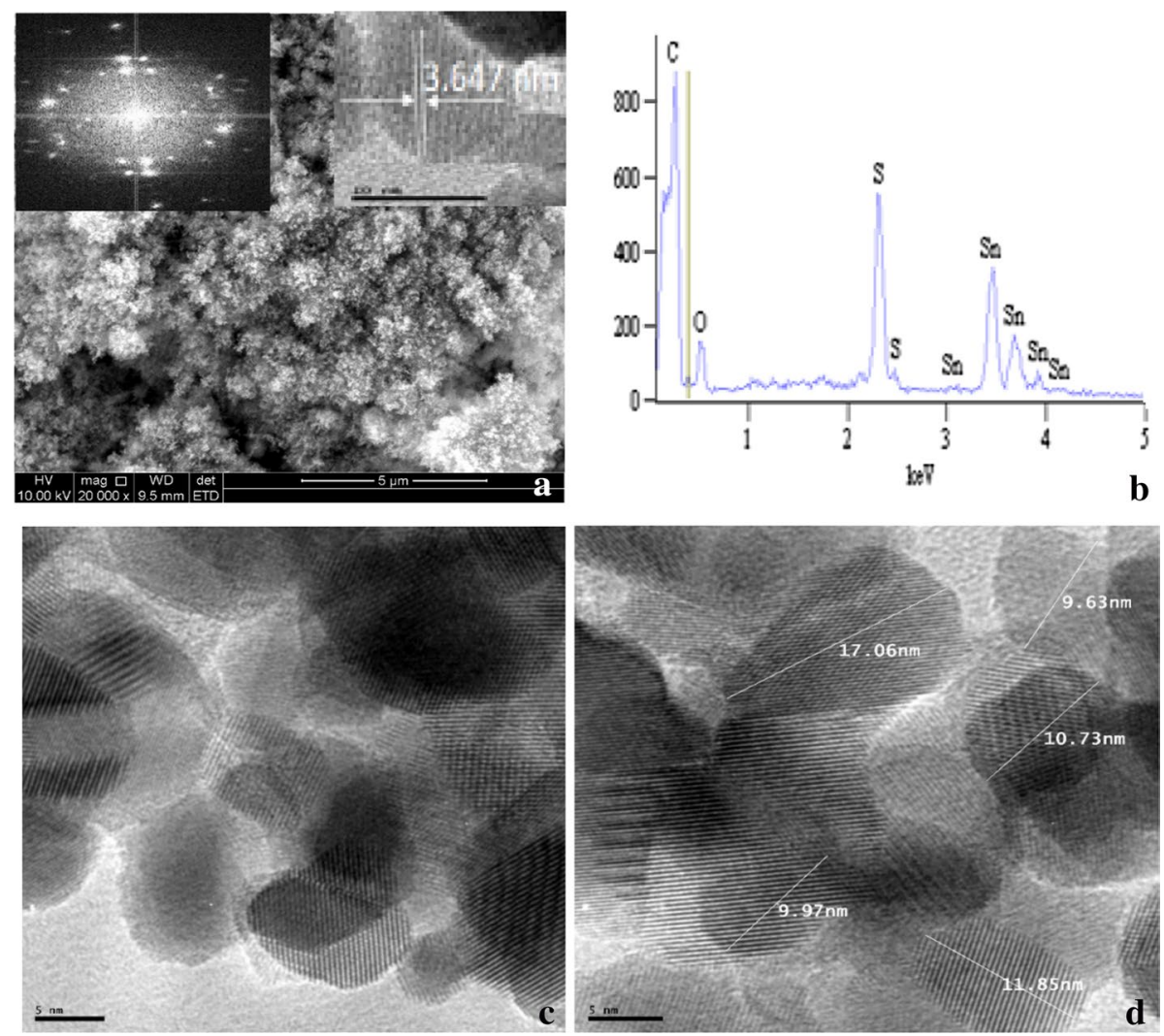

Fig. 5 SEM images SnS nanocrystals a EDS spectrum with observed elements, b SEM image at $\times 10,000$ magnification, c HRTEM images of SnS nanocrystals showing fringes with inset selected area electron diffraction (SAED) pattern and $3.647 \mathrm{~nm}$ d-spacing, $\mathbf{d}$ HRTEM image showing particle sizes 
Fig. 5c). The average diameter of nanocrystals is around $11.85 \pm 3.04 \mathrm{~nm}$ (shown in Fig. $5 \mathrm{~d}$ ). The EDS spectrum (EDS spectrum of observed elements in Fig. 5a) shows the presence of tin, sulfur, carbon and oxygen in the nanocrystals. SEM micrograph images in Fig. (a) and (b) in different magnification, confirms the formation nanosheets (Xiong et al. 2017).

The optical properties of SnS nanocrystals revealed a better absorption of light in the entire visible region as depicted in Fig. 6a. Photoluminescence spectrum (Fig. 6b) showed strong band edge emission peak at $460 \mathrm{~nm}$ assigned to tin and sulphur vacancies associated to interstitial defects (Gandhimathi et al. 2019; Warrier and Gandhimathi 2018).

Tauc plots was used to estimate the indirect and direct energy band gap from optical absorption spectrum as displayed in Fig. 6c, d. The optical absorption theory revealed the link between the absorption coefficient $(\alpha)$ and the photon energy $(\mathrm{h} \nu)$ as follow (Mbese et al. 2019):

$$
(\alpha h \nu)^{\mathrm{n}}=A(h \nu-E g)
$$

where $A$ is constant, $\mathrm{n}$ is the number that depends on the electronic transition (Mbese et al. 2019). Where $\mathrm{n}$ is $1 / 2$ and 2 for indirect and direct transition, respectively. The indirect and
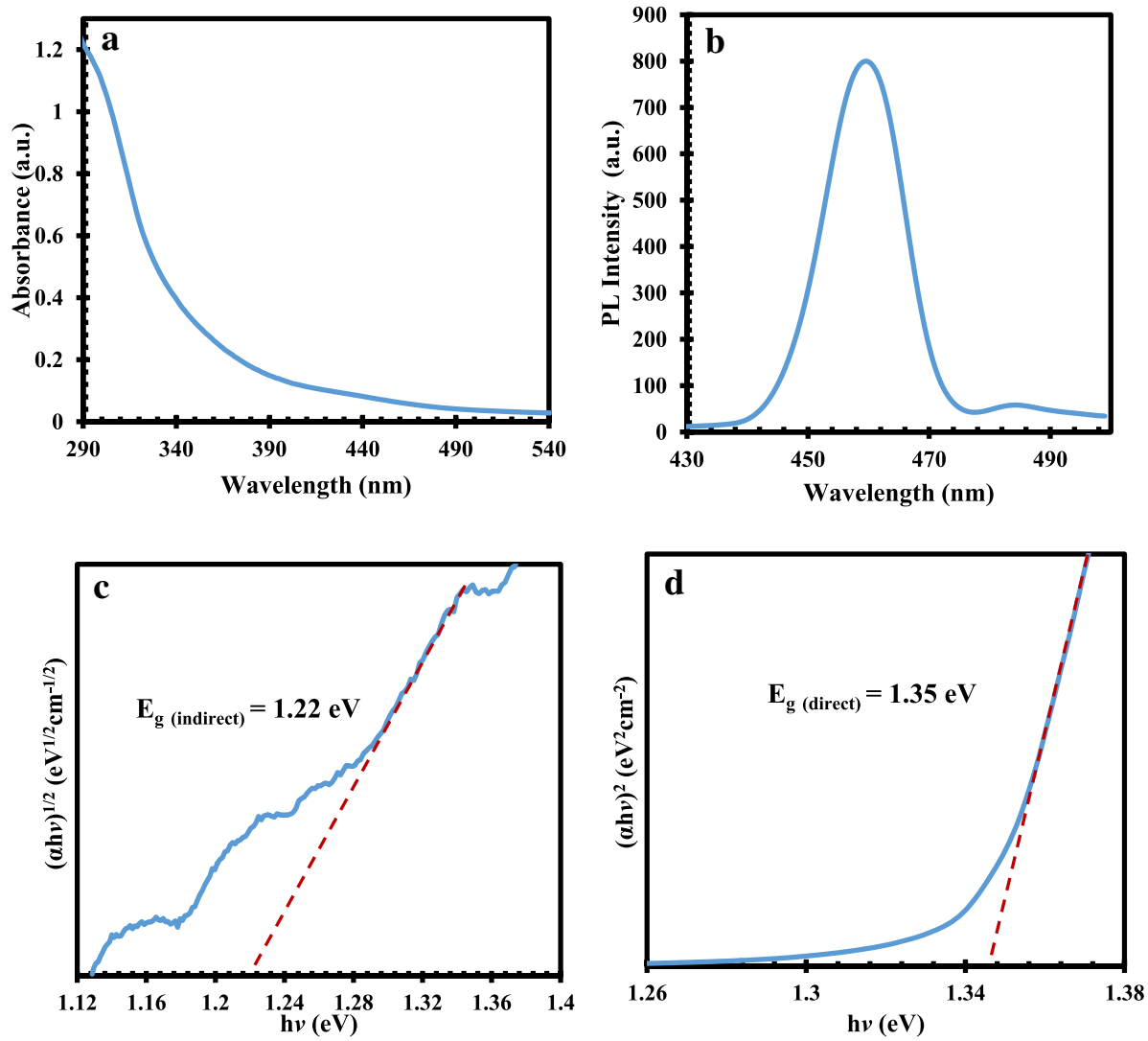

Fig. 6 Optical properties of SnS nanocrystals: a UV-vis absorption spectrum, b photoluminescence (PL) showing an emission max. at $462 \mathrm{~nm}$, c Tauc plot showing the dependence $(\alpha \mathrm{h} v)^{1 / 2}$ on photon energy (hv), d Tauc plot showing the dependence $(\alpha h v)^{2}$ on photon energy $(\mathrm{h} v)$ 
direct energy band gap was found to be 1.22 and $1.35 \mathrm{eV}$, respectively. A red shifted of 0.28 and $0.15 \mathrm{eV}$ compared to the bulk SnS, respectively. The observed red shift arises due to the effect of quantum confinement.

\section{Conclusions}

Nanosheets of high-quality SnS monodispersed nanocrystals have been synthesized from thermal decomposition of precursor complex using TGA. The thermal decomposition behaviour of precursor complex revealed three staged degradations leading to the formation of SnS nanocrystals. The TGA observed values are in good agreement with theoretical values, indicating high thermal stability of the precursor complex. The powder X-ray diffraction pattern confirmed the orthorhombic structure of SnS nanocrystals with average particle size diameter around $14 \mathrm{~nm}$. Raman shifts revealed $\mathrm{B}_{2 \mathrm{~g}}, \mathrm{~A}_{\mathrm{g}}$ and $\mathrm{B}_{3 \mathrm{~g}}$ modes corresponding to $\mathrm{SnS}$ nanocrystals which is attributed to phonon confinement. All modes observed are corresponding to the $\mathrm{SnS}$ nanocrystal modes which further cemented the XRD spectra. HRTEM images clearly displayed defined lattice fringes with a d-spacing of $3.647 \mathrm{~nm}$, corresponding to the (111) planes. SAED pattern exhibiting distinct diffraction rings corresponding to the (111), (200), and (311) of the orthorhombic phase of SnS nanocrystals. PL showed strong band edge emission peak at $460 \mathrm{~nm}$ ascribed to tin and sulphur vacancies associated to interstitial defects. Red shifted indirect and direct energy band gaps of 1.22 and $1.35 \mathrm{eV}$ were observed compared to the bulk $\mathrm{SnS}$, due to the effect of quantum confinement. From optical, structural, and electron microscopy results, it can be concluded that $\mathrm{SnS}$ nanocrystals are promising materials for solar cell applications.

Acknowledgements The authors wish to acknowledge the National Department of Science and Technology (GUN: 86187) of South Africa and its implementing agent, the National Research Foundation (GUN: 93215) for the financial support. Authors are also grateful for the financial support by Govan Mbeki Research and Development Centre (GMRDC), University of Fort Hare, South Africa and NRF Thuthuka Grant (GUN: 118139). Funding was provided by Eskom Capacity Development Funding (Grant No. P948).

Open Access This article is licensed under a Creative Commons Attribution 4.0 International License, which permits use, sharing, adaptation, distribution and reproduction in any medium or format, as long as you give appropriate credit to the original author(s) and the source, provide a link to the Creative Commons licence, and indicate if changes were made. The images or other third party material in this article are included in the article's Creative Commons licence, unless indicated otherwise in a credit line to the material. If material is not included in the article's Creative Commons licence and your intended use is not permitted by statutory regulation or exceeds the permitted use, you will need to obtain permission directly from the copyright holder. To view a copy of this licence, visit http://creativecommons.org/licenses/by/4.0/.

\section{References}

Akbari, T., Rozati, S.M.: Preparation and growth of SnS thin film deposited by spray pyrolysis technique. J. Solid State Chem. 22, 33-39 (2015)

Al-Shakban, M., Matthews, P.D., Lewis, E.A., Raftery, J., Vitorica-Yrezabal, I., Haigh, S.J., Lewis, D.J., O’Brien, P.: Chemical vapor deposition of tin sulfide from diorganotin (IV) dixanthates. J. Mater. Sci. 54, 2315-2323 (2019)

Awang, N., Farahana, N.K., Baba, I., Hamid, A.: Synthesis, characterization, and antitumor activity of new organotin (IV) methoxyethyldithiocarbamate complexes. Orient. J. Chem. 32, 101-107 (2016)

Baig, F., Khattak, Y.H., Soucase, B.M., Beg, S., Khani, N.A.K.: Efficiency limits of SnS thin film solar cells. Mater. Focus 7, 807-813 (2018) 
Banai, R.E., Cordell, J.C., Lindwall, G., Tanen, N.J., Shang, S.L., Nasr, J.R., Liu, Z.K., Brownson, J.R., Horn, M.W.: Control of phase in tin sulfide thin films produced via RF-sputtering of $\mathrm{SnS}_{2}$ target with post-deposition annealing. J. Electron. Mater. 45, 499-508 (2016)

Chowdhury, A.P., Shambharkar, B.H., Ghugal, S.G., Umare, S.S., Shende, A.G.: Ethylene glycol mediated synthesis of $\mathrm{SnS}$ quantum dots and their application towards degradation of eosin yellow and brilliant green dyes under solar irradiation. RSC Adv. 6, 108290-108297 (2016)

Cifuentes, C., Botero, M., Romero, E., Calderon, C., Gordillo, G.: Optical and structural studies on SnS films grown by co-evaporation. Braz. J. Phys. 36, 1046-1049 (2006)

Devika, M., Reddy, N.K., Reddy, S.V., Ramesh, K., Gunasekhar, K.R.: Influence of rapid thermal annealing (RTA) on the structural and electrical properties of SnS films. J. Mater. Sci. Mater. 20, 1129-1134 (2009)

Gandhimathi, R., Anitha, D., Warrier, A.R.: Photoluminescence in degenerate states of heavily doped SnS nanoparticles. AIP Conf. Proc. 2115, 030475 (2019)

Greyson, E.C., Barton, J.E., Odom, T.W.: Tetrahedral zinc blende tin sulfide nano and microcrystals. Small 2, 368-371 (2006)

Henry, J., Mohanraj, K., Kannan, S., Barathan, S., Sivakumar, G.: Effect of selenium doping on structural and optical properties of SnS: Se thin films by electron beam evaporation method. Eur. Phys. J. Appl. Phys. 61, 10301 (2013)

Henry, J., Mohanraj, K., Kannan, S., Barathan, S., Sivakumar, G.: Structural and optical properties of SnS nanoparticles and electron-beam-evaporated SnS thin films. J. Exp. Nanosci. 10, 78-85 (2015)

Hickey, S.G., Waurisch, C., Rellinghaus, B., Eychmüller, A.: Size and shape control of colloidally synthesized IV-VI nanoparticulate tin (II) sulphide. J. Am. Chem. Soc. 130, 14978-14980 (2008)

Ichimura, M., Takeuchi, K., Ono, Y., Arai, E.: Electrochemical deposition of SnS thin films. Thin Solid Films 361, 98-101 (2000)

Ilkhechi, N.N., Alijani, M., Kaleji, B.K.: Optical and structural properties of $\mathrm{TiO}_{2}$ nanopowders with $\mathrm{Co} / \mathrm{Ce}$ doping at various temperature. Opt. Quantum Electron. 48, 148-157 (2016)

Jamali-Sheini, F., Cheraghizade, M., Yousefi, R.: Ultrasonic synthesis of In-doped SnS nanoparticles and their physical properties. Solid State Sci. 79, 30-37 (2018)

Kafashan, H., Azizieh, M., Balak, Z.: Electrochemical synthesis of nanostructured Se-doped SnS: effect of Se-dopant on surface characterizations. Appl. Surf. Sci. 410, 186-195 (2017)

Kawano, Y., Chantana, J., Minemoto, T.: Impact of growth temperature on the properties of SnS film prepared by thermal evaporation and its photovoltaic performance. Curr. Appl. Phys. 15, 897-901 (2015)

Kevin, P., Lewis, D.J., Raftery, J., Malik, M.A., O'Brien, P.: Thin films of tin (II) sulphide (SnS) by aerosolassisted chemical vapour deposition (AACVD) using tin (II) dithiocarbamates as single-source precursors. J. Cryst. Growth 415, 93-99 (2015)

Koteeswara Reddy, N., Hahn, Y.B., Devika, M., Sumana, H.R., Gunasekhar, K.R.: Temperature-dependent structural and optical properties of SnS films. J. Appl. Phys. 101, 093522 (2007)

Kumar, K.S., Manohari, A.G., Dhanapandian, S., Mahalingam, T.: Physical properties of spray pyrolyzed Ag-doped SnS thin films for opto-electronic applications. Mater. Lett. 131, 167-170 (2014)

Mbese, J., Ajibade, P.: Preparation and characterization of $\mathrm{ZnS}, \mathrm{CdS}$ and $\mathrm{HgS} /$ poly (methyl methacrylate) nanocomposites. Polymers 6, 2332-2344 (2014)

Mbese, J.Z., Ajibade, P.A.: Synthesis, spectroscopic, structural and optical studies of $\mathrm{Ru}_{2} \mathrm{~S}_{3}$ nanoparticles prepared from single-source molecular precursors. J. Mol. Struct. 1143, 274-281 (2017)

Mbese, J.Z., Ajibade, P.A.: A simple route to ruthenium sulfide nanoparticles via thermal decomposition of precursor complexes. J. NanoRes. 54, 158-171 (2018)

Mbese, J.Z., Ajibade, P.A., Matebese, F., Agoro, M.A.: Optical and structural properties of TOPO/HDA capped Cus nanocrystals via thermal decomposition of bis (N-diisopropyldithiocarbamate) $\mathrm{Cu}$ (II) complex. J. Nano Res-Sw. 59, 161-165 (2019)

Muthalib, A.F., Baba, I., Farina, Y., Samsudin, M.W.: Synthesis and characterization of diphenyltin (IV) dithiocarbamate compounds. Malaysian J. Anal. Sci. 15, 106-112 (2011)

Ninan, G.G., Kartha, C.S., Vijayakumar, K.P.: On the preparation of n-type SnS: Cu using chemical spray pyrolysis for photovoltaic application: effect of annealing. Sol. Energy Mater. Sol. Cells 157, 229-233 (2016)

Oda, Y., Shen, H., Zhao, L., Li, J., Iwamoto, M., Lin, H.: Energetic alignment in nontoxic SnS quantum dotsensitized solar cell employing spiro-OMeTAD as the solid-state electrolyte. Sci. Technol. Adv. Mater. 15, 035006 (2014)

Park, J., Hwang, C.H., Lee, W.Y., Kim, Y., Kim, H., Shim, I.W.: Preparation of size-tunable SnS nanoparticles by a sonochemical method under multibubble sonoluminescence conditions. Mater. Lett. 117, 188-191 (2014) 
Sall, T., Mollar, M., Marí, B.: Substrate influences on the properties of SnS thin films deposited by chemical spray pyrolysis technique for photovoltaic applications. J. Mater. Sci. 51, 7607-7613 (2016)

Sebastian, S., Kulandaisamy, I., Arulanantham, A.M.S., Valanarasu, S., Kathalingam, A., Shkir, M., AlFaify, S.: Enhancement in photovoltaic properties of Nd: SnS films prepared by low-cost NSP method. Rare Met. (2019). https://doi.org/10.1007/s12598-019-01295-2

Seol, J.S., Lee, S.Y., Lee, J.C., Nam, H.D., Kim, K.H.: Electrical and optical properties of $\mathrm{Cu}_{2} \mathrm{ZnSnS}_{4}$ thin films prepared by rf magnetron sputtering process. Sol. Energy Mater. Sol. Cells 75, 155-162 (2003)

Shao, Z., Shi, C., Chen, J., Zhang, Y.: Preparation of SnS thin films with gear-like sheet appearance by close-spaced vacuum thermal evaporation. Int. J. Mod. Phys. B 31, 1744054 (2017)

Sohila, S., Rajalakshmi, M., Muthamizhchelvan, C., Kalavathi, S., Ghosh, C., Divakar, R., Venkiteswaran, C.N., Muralidharan, N.G., Arora, A.K., Mohandas, E.: Synthesis and characterization of SnS nanosheets through simple chemical route. Mater. Lett. 65, 1148-1150 (2011)

Stavrinadis, A., Smith, J.M., Cattley, C.A., Cook, A.G., Grant, P.S., Watt, A.A.: SnS/PbS nanocrystal heterojunction photovoltaics. Nanotechnology 21, 185-202 (2010)

Talapin, D.V., Lee, J.S., Kovalenko, M.V., Shevchenko, E.V.: Prospects of colloidal nanocrystals for electronic and optoelectronic applications. Chem. Rev. 110, 389-458 (2009)

Tang, P., Chen, H., Cao, F., Pan, G., Wang, K., Xu, M., Tong, Y.: Nanoparticulate SnS as an efficient photocatalyst under visible-light irradiation. Mater. Lett. 65, 450-452 (2011)

Tang, R., Su, H., Sun, Y., Zhang, X., Li, L., Liu, C., Zeng, S., Sun, D.: Enhanced photocatalytic performance in $\mathrm{Bi}_{2} \mathrm{WO}_{6} / \mathrm{SnS}$ heterostructures: facile synthesis, influencing factors and mechanism of the photocatalytic process. J. Colloid Interface Sci. 466, 388-399 (2016)

Tanusevski, A.: Optical and photoelectric properties of SnS thin films prepared by chemical bath deposition. Semicond. Sci. Technol. 18, 501-505 (2003)

Vaughn, D.D., Hentz, O.D., Chen, S., Wang, D., Schaak, R.E.: Formation of SnS nanoflowers for lithium ion batteries. Chem. Commun. 48, 5608-5610 (2012)

Wang, J., Lian, G., Xu, Z., Fu, C., Lin, Z., Li, L., Wang, Q., Cui, D., Wong, C.P.: Growth of large-size SnS thin crystals driven by oriented attachment and applications to gas sensors and photodetectors. ACS Appl. Mater. Int. 8, 9545-9551 (2016)

Wang, S.F., Wang, W., Fong, W.K., Yu, Y., Surya, C.: Tin compensation for the SnS based optoelectronic devices. Sci. Rep. 7, 39704 (2017)

Warrier, A.R., Gandhimathi, R.: Influence of surface plasmon resonance of Sn nanoparticles and nanosheets on the photoluminescence and Raman spectra of SnS quantum dots. AIP Conf. Proc. 1942, 140082 (2018)

Xiong, X., Yang, C., Wang, G., Lin, Y., Ou, X., Wang, J.H., Zhao, B., Liu, M., Lin, Z., Huang, K.: SnS nanoparticles electrostatically anchored on three-dimensional $\mathrm{N}$-doped graphene as an active and durable anode for sodium-ion batteries. Energy Environ. Sci. 10, 1757-1763 (2017)

$\mathrm{Xu}$, Y., Al-Salim, N., Tilley, R.D.: Synthesis and size dependent reflectance study of water soluble SnS nanoparticles. Nanomaterials 1, 54-64 (2012)

Zhao, E., Gao, L., Yang, S., Wang, L., Cao, J., Ma, T.: In situ fabrication of 2D $\mathrm{SnS}_{2}$ nanosheets as a new electron transport layer for perovskite solar cells. Nano Res. 11, 5913-5923 (2018)

Zhou, X., Gan, L., Zhang, Q., Xiong, X., Li, H., Zhong, Z., Han, J., Zhai, T.: High performance near-infrared photodetectors based on ultrathin $\mathrm{SnS}$ nanobelts grown via physical vapor deposition. J. Mater. Chem. C. 4, 2111-2116 (2016)

Publisher's Note Springer Nature remains neutral with regard to jurisdictional claims in published maps and institutional affiliations. 